\section{Herbal flavonoids inhibit the development of autoimmune diabetes in NOD mice: proposed mechanisms of action in the example of PADMA 28}

\author{
Lola Weiss,' Vivian Barak,, Itamar Raz,, \\ Reuven Or,' Shimon Slavin,' \\ Isaac Ginsburg ${ }^{4}$ \\ 'Dept. Bone Marrow Transplantation \& \\ Cancer Immunology, Hadassah Hospital, \\ Jerusalem; ' 2 mmunology Laboratory for \\ Tumor Diagnosis, Dept. Oncology, \\ Hadassah Hospital, Jerusalem; \\ ${ }^{3}$ Diabetes Research Unit, Division of \\ Internal Medicine, Hadassah Hospital, \\ Jerusalem; ${ }^{4}$ Institute of Dental Sciences, \\ Hebrew University Hadassah, Faculty of \\ Dental Medicine, Ein Kerem Campus, \\ Jerusalem, Israel
}

\section{Abstract}

Padma ${ }^{\circledR} 28$ is a multicompound herbal preparation based on the camphor formulas from traditional tibetan medicine (TTM). It contains a variety of different secondary plant substances, which include terpenes and polyphenols such as flavonoids and tannins. The formula is used in various chronic inflammatory diseases. The aim of this study was to investigate whether secondary plant substances as present in Padma 28 are able to prevent the development of autoimmune diabetes. Female NOD mice were administered an aqueous Padma 28 extract intraperitonneally (i.p.), subcutaneously (s.c.) or per os (p.o.) over a period of 13 weeks. The development of autoimmune diabetes mellitus type 1 was monitored over 24 weeks. Untreated and saline treated mice served as controls. After 24 weeks, $20 \%$ of the control groups were free of diabetes while $100 \%$ and $80 \%$ of the animals administered aqueous extracts from Padma 28 i.p. or s.c., respectively, were diabetes-free. In the p.o. group, $33 \%$ were diabetes-free. In controls, only a few pancreatic islets had survived. Animals treated i.p. with Padma 28 had preserved islets with minimal lymphocyte infiltrations. Spleen cells from animals treated i.p. or s.c. with Padma 28 and stimulated with concanavalin A showed significant elevations in the levels of interleukins (IL)-10, IL-6 and IL-4. In the plasma, the level of the Th1 cytokine IL-12 was decreased in the i.p. group. Padma 28 treatment by the i.p. route of administration showed a significant decrease in CD8 cytotoxic cells, which have been implicated in the destruction of the islets. The findings support the use of secondary plant substances such as flavonoids in inflammatory autoimmune diseases. The results suggest that Padma 28 has immunomodulatory effects associated with a shift from Th1 to Th2 immune response and may have protective effects against autoimmune diabetes.

\section{Introduction}

Padma $^{\circledR} 28$ (PADMA Inc. Schwerzenbach, Switzerland) is a herbal multi-component preparation, which is produced as a commercial product according to international quality guidelines in Switzerland. Each batch of components is validated regarding identity and quality according to the European Pharmacopoeia or, if not applicable, to manufacturer's specifications, which are deposited at the Swiss authorities for the authorization and supervision of therapeutic products (Swissmedic). The herbal formulation is rich in secondary plant substances, such as essential oils, flavonoids, and tannins.

Padma 28 has been successfully used in different chronic inflammatory diseases and has also shown anti-inflammatory effects in various in vitro studies. ${ }^{1-6}$ Inflammation plays an important role in the pathogenesis of type 1 diabetes mellitus, an autoimmune disorder characterized by the destruction of pancreatic beta-islets, resulting in insulin deficiency and hyperglycemia. Female non-obese diabetic (NOD) mice spontaneously develop autoimmune diabetes and are considered an experimental model for human type 1 diabetes mellitus ${ }^{7,8}$ Histological examination of the pancreas from NOD mice revealed characteristic mononuclear cell infiltrations of the islets, predominantly by $\mathrm{T}$ cells, resulting in autoimmune insulitis and low functional islets. As in many other autoimmune diseases, cytokines secreted by macrophages and lymphocytes are also thought to be involved in the development of diabetes. ${ }^{9,10}$ While the administration of INF- $\gamma$ can cause or accelerate autoimmune disease in NOD animals, anti-inflammatory cytokines such as interleukin IL-10 may have protective effects. $^{9,11,12}$ In mice, IL-10 produced by the Th2 subset of $\mathrm{CD}^{+}$T-helper lymphocytes, Lyl+B lymphocytes, and macrophages ${ }^{13,14}$ inhibited proliferation of Th1 cell-derived INF- $\gamma$ and IL-2 by blocking co-stimulatory functions of accessory cells. Several agents capable of suppressing the development of diabetes in laboratory animals, possibly due to a modulation of the cytokine production (imbalance between Th1/Th2 responses), have been described. ${ }^{12}$ Since reactive oxygen and nitrogen species are also implicated in the pathophysiology of diabetes ${ }^{15-18}$ and since oxidants were found to synergize with proteases, membrane-damaging agents and with certain cytokines to injure
Correspondence: Isaac Ginsburg, the Hebrew University of Jerusalem, Oral Biology, Faculty of Dental Medicine, 91120 Jerusalem, Israel.

E-mail: ginsburg@cc.huji.ac.il

Key words: herbal flavonoids, Padma 28, tibetan medicine, autoimmune diabetes, NOD mouse cytokines

Received for publication: 18 August 2010.

Revision received: 24 September 2010.

Accepted for publication: 24 September 2010 .

Acknowledgments: this work was supported by an endowment fund to Isaac Ginsburg from the late Dr. S.M. Robbins of Cleveland, OH, USA.

We thank Susana Reich for her skilled technical support and Prof. Nurit Kaiser for helping in the determination of insulin levels.

This work is licensed under a Creative Commons Attribution 3.0 License (by-nc 3.0).

(OCopyright L. Weiss et al., 2011

Licensee PAGEPress, Italy

Alternative Medicine Studies 2011; 1:e1

doi:10.4081/ams.2011.el

mammalian cells, ${ }^{19}$ it was postulated that herbal preparations rich in anti-oxidants, bioflavonoids and anthocyanidins, might be able to inhibit the development of diabetes.

To investigate whether secondary plant substances such as herbal flavonoids are able to prevent the development of autoimmune diabetes, we analyzed the formula Padma 28 in a pre-clinical model of the autoimmune disorder type 1 diabetes mellitus.

\section{Materials and Methods}

\section{Padma 28 extracts}

Padma 28 is produced by PADMA Inc. according to GMP guidelines in Switzerland. It is distributed in several European countries as well as in Canada and the USA for oral use. The formula contains: Bengal quince (Aegle marmelos (L.) Correa) $20 \mathrm{mg}$, allspice (Pimenta dioica (L.) Merr.) $25 \mathrm{mg}$, columbine (Aquilegia vulgaris $L$.) $15 \mathrm{mg}$, calcium sulphate $20 \mathrm{mg}$, calendula flower head (Calendula officinalis L.) $5 \mathrm{mg}$, natural camphor (Cinnamomum camphora (L.) Sieb.) $4 \mathrm{mg}$, cardamom fruit (Elettaria cardamomum (L.) Maton) $30 \mathrm{mg}$ clove (Syzygium aromaticum (L.) Merril et L.M. Perry) $12 \mathrm{mg}$, costus root (Saussurea lappa C.B. Clarke) $40 \mathrm{mg}$, kempferia galanga rhizome (Kaempferia galanga L.) $10 \mathrm{mg}$, lettuce leaf (Lactuca sativa L.) $6 \mathrm{mg}$, Iceland moss (Cetraria islandica (L.) Ach.) $40 \mathrm{mg}$, liquorice root (Glycyrrhiza glabra L.) $15 \mathrm{mg}$, neem fruit 
(Azadirachta indica A. Juss.) $35 \mathrm{mg}$, chebulic myrobalan fruit (Terminalia chebula Retz.) 30 $\mathrm{mg}$, ribwort plantain (Plantago lanceolata L.) $15 \mathrm{mg}$, common knotgrass (Polygonum aviculare L.) $15 \mathrm{mg}$, potentilla golden herb (Potentilla aurea L.) $15 \mathrm{mg}$, red sandalwood (Pterocarpus santalinus L.f.) $30 \mathrm{mg}$, heart-leaf sida (Sida cordifolia L.) $10 \mathrm{mg}$, monkshood (Aconitum napellus L.) $1 \mathrm{mg}$, valerian root (Valeriana officinalis L. s.l.) $10 \mathrm{mg}$ per tablet. Padma 28 was supplied by PADMA Inc. (Schwerzenbach, Switzerland) as a powdered mixture without excipients.

A total of $4.05 \mathrm{~g}$ of Padma 28 was mixed with $100 \mathrm{~mL}$ of sterile distilled water and stirred for $30 \mathrm{~min}$ at $22^{\circ} \mathrm{C}$ on a magnetic mixer. The suspension was centrifuged at $2,000 \mathrm{~g}$ for $10 \mathrm{~min}$ to remove non-extractable agents. It was then filtered through a Whatman 41 filter paper, shell frozen and lyophilized. Approximately $12-15 \%$ of the powdered herbal preparation was solubilized. Sterility was determined by routine assays on different culture media (blood agar, brain heart infusion agar and McConkey's medium).

\section{NOD mice}

Nine to fifteen 5-6 week old female NOD mice were tested per group. The animals were purchased from Harlen Breeding Facility, Jerusalem, Israel. The animals were fed standard laboratory chow ad libitum, and were kept in an SPF animal house facility.

\section{Padma 28 administration and \\ development of overt diabetes}

Five groups of NOD mice were used in a trial that lasted 24 weeks. Group I (15 animals) was left untreated, Group II (15 animals) served as control and was administered $0.2 \mathrm{~mL}$ saline i.p. 5 times during the first week, and then received one injection of saline per week for a total of four weeks. One month later, $0.3 \mathrm{ml}$ of saline was given once a week and two weeks later, 0.25 $\mathrm{mL}$ of saline was given once a week for three additional weeks. Group III (15 animals) was administered i.p. $0.3 \mathrm{~mL}$ (3 mg dry weight of Padma 28) 3 times during the first week. Additional injections of Padma 28 were given according to the schedule described for group II. Group IV (10 animals) was administered 250 $\mathrm{mg} / \mathrm{kg}$ Padma 28 s.c. according to the schedule described for group II. Group V (9 animals) received $7 \mathrm{mg}$ Padma 28 p.o. via a gastric tube 5 times during the first week and then according to the time schedule described for group II.

All mice were monitored daily, and urine was analyzed for the presence of glucose once or twice a week using a standard glucose stick (Medi-Test Combi 9 Macherey-Nagel, Duren, Germany). The development of overt diabetes was confirmed and considered positive only if on two separate occasions the level of glucose in the urine was greater than $1,000 \mathrm{mg} / \mathrm{dL}$.

\section{Intraperitoneal glucose tolerance test}

Mice that had survived for 24 weeks without developing overt diabetes (glucosuria negative) were administered D-glucose at $1 \mathrm{~g} / \mathrm{kg}$ body weight i.p. Blood glucose levels were determined with a Glucometer Elite apparatus (Bayer Diagnostics, Elkart, IN, USA) at 0 and 60 min after glucose injection. Animals with glucose levels greater than $140 \mathrm{mg} / \mathrm{dL}$ at $60 \mathrm{~min}$ were considered as having latent diabetes.

\section{Quantitative analysis of insulin in \\ pancreas}

Animals were sacrificed at week 24 , the pancreas was immediately removed and the head portion was frozen at $-70^{\circ} \mathrm{C}$ for the subsequent analysis of insulin content following acidethanol extraction, as described previously. ${ }^{20}$ The remaining part of the pancreas was fixed in $10 \%$ phosphate-buffered formalin and embedded in paraffin. Multiple consecutive sections of $5 \mu \mathrm{m}$ were stained with hematoxylin and eosin for histology or prepared for immunohistochemical analysis, as outlined below.

Insulin content was determined by radioimmunoassay, using anti-insulin coated test tubes (ICN Pharmaceuticals, Costa Mesa, CA, USA) and 125I-insulin (Linco Research, St. Charles, M0, USA). The routine intra-assay coefficient of variation (CV) was $4-6 \%$, the inter-assay CV was 6-10\%. Rat insulin standards (Novo-Nordisk, Bagsvaerd, Denmark), were used for the determination of mouse insulin-like immunoreactivity.

\section{Immunohistochemical analysis for} the presence of insulin in the pancreas

The presence of diabetes was also confirmed by histological examination of the pancreas, as described previously. ${ }^{21}$ Briefly, de-paraffinized sections were rinsed with phosphate buffered saline (PBS) and endogenous peroxidase was blocked by exposure to $3 \% \mathrm{H}_{2} \mathrm{O}_{2}$ for $15 \mathrm{~min}$ at room temperature. Insulin-containing cell sections were then incubated with a 1:100 dilution of guinea-pig anti-insulin antibody (Sigma, Rehovot, Israel) at $37^{\circ} \mathrm{C}$ for $1 \mathrm{~h}$, and detected using a streptavidin-biotin peroxidase complex developed with aminoethylcarbazole substrate (Zymed, San Francisco, CA, USA). Two sections per animal were evaluated by light microscopy at x200 magnification.

\section{Evaluation of cytokines production}

Cytokine production was evaluated in plasma and in supernatant fluids from cultured spleen cells. Spleen cells were stimulated with $2.5 \mathrm{mg} / \mathrm{mL}$ concanavalin A (Con A) and cytokines were analyzed after 24 and after $48 \mathrm{~h}$.
The levels of the Th1 cytokines IL-12 and interferon (INF) $-\gamma$ and of the Th2 cytokines IL-10 and IL- 6 were measured by a solid phase ELISA (R \& D, Minneapolis MN, USA) using a quantitative sandwich enzyme immunoassay technique as described previously. ${ }^{1}$

\section{Proliferative response detected by ${ }^{3} \mathrm{H}$-thymidine incorporation}

Spleen cells obtained from NOD mice were teased into single cell suspensions on a nylon mesh and then suspended in Hank's buffer. Cell viability was determined by trypan blue exclusion. A spleen cell suspension from each mouse was prepared in RPMI-1640 (Biological Industries, Bet Haemek, Israel) containing 10\% fetal calf plasma (FCS) (GIBCO, Grand Island NY, USA). Cells were washed twice, counted and were seeded in the concentration of $5 \times 10^{5}$ cells per well in triplicate. They were cultured for three days in flat bottomed 96-well micro plates in the presence of $2.5 \mu \mathrm{g} / \mathrm{mL}$ Con A (Bio Makor, Rehovot, Israel). Twenty hours before harvesting, $1 \mu \mathrm{Ci} 3 \mathrm{H}$-thymidine (specific activity $5 \mathrm{mCi} / \mathrm{mmoL}$, Nuclear Research Center, Negev, Israel) was added. The proliferative response was determined by measuring the incorporation of ${ }^{3} \mathrm{H}$-thymidine. The data were expressed as an index of Con A treated/ unstimulated cells.

\section{Fluorescence-activated cell sorter analysis}

Single cell suspensions of individual spleen cells from NOD mice were analyzed for cell surface markers as follows: $50 \mu \mathrm{L}$ of cell suspension $\left(10^{6}\right.$ cells) in PBS containing $0.1 \%$ sodium azide and $2 \%$ FCS were mixed with $10 \mu \mathrm{L}$ fluorescein isothiocyanate (FITC)-conjugated monoclonal anti-CD4 antibodies (recognizes Thelper cells) and anti-CD8 antibodies (recognizes cytotoxic T cells). Anti-mouse CD25 (expressed by activated $\mathrm{T}$ and $\mathrm{B}$ lymphocytes and NK cells but not by resting T, B, or NK cells), anti-mouse CD69-FITC (recognizes activated T, B and NK cells) and anti-Mac-1 (recognizes a differentiation antigen stimulated on mononuclear phagocytes and granulocytes) were purchased from Pharmigen, San Diego, CA, USA. Hamster anti-mouse CD69 was purchased from Serotec 0xford, UK. The cell mixtures were incubated for 30 min on ice, washed twice, and resuspended in $0.2 \mathrm{~mL}$ PBS containing $0.1 \%$ sodium azide. After correcting for non-specific staining, the percentage of cells staining positively for the various markers was determined by FACS analysis (FACS, 440, Becton-Dickinson Franklin Lakes, NJ, USA).

\section{Statistical analysis}

The Mann-Whitney $U$ test was used for between group comparisons. $\mathrm{P}<0.05$ was considered significant. 


\section{Results}

Effect of Padma 28 on the survival and development of overt diabetes in NOD mice

After 24 weeks, $100 \%$ of the animals injected i.p. with Padma $28,80 \%$ of the animals injected s.c. with Padma 28, and $33 \%$ of the animals administered Padma 28 p.o. were free of diabetes (Figure 1). On the other hand, only $20 \%$ of the animals in the untreated and in the saline control groups were diabetes-free. In Padma 28 treated animals that developed autoimmune diabetes, the onset of the signs of the disease was delayed by four days in the p.o. treated animals (first signs on day 16 compared to day 12 in controls) and by one week in the s.c. treated animals (first signs appeared on day 18).

\section{Glucose tolerance test}

All the animals that had survived by the end of the trial and showed no glucosuria underwent an i.p. glucose tolerance test. Overt diabetes was confirmed only if on two occasions the glucose levels in urine exceeded $1,000 \mathrm{mg} / \mathrm{dL}$. Of the 4 untreated animals which had survived, 2 were diabetes free and 2 animals had latent diabetes. In the saline treated group, 2 of 4 mice had overt diabetes, and one animal had latent diabetes. In the Padma 28 group treated i.p., 4 of the 11 surviving animals had latent diabetes and 7 were diabetes free. In the group receiving Padma 28 s.c., 8 survived, none had overt diabetes and 3 had latent diabetes. Finally, in the group administered Padma 28 p.o., only 3 survived for 24 weeks and all had latent diabetes.

\section{Quantitative analysis of insulin in the pancreas}

Whereas a very marked depletion of insulin content was observed in untreated animals with an average of $0.198 \mathrm{pmol} / \mathrm{mg}$ tissue $(\mathrm{n}=4)$, the pancreata of normal mice $(n=4)$ and of mice treated i.p. with Padma $28(n=5)$ had a large insulin content of $300 \mathrm{pmol} / \mathrm{mg}$.

\section{Staining of pancreatic islets with anti-insulin antibodies}

While only a very few insulin-positive beta cells were found in untreated mice, the surviving animals administered Padma 28 exhibited preserved islet morphology with multiple insulin-containing cells. Thus, the histochemical analysis paralleled the quantitative analysis of insulin in the pancreas (data not shown).

\section{The proliferative responses of spleen cells to Con A}

As T cells are involved in the pathophysiology of type 1 diabetes, the proliferative response of $\mathrm{T}$ cells derived from control and from Padma

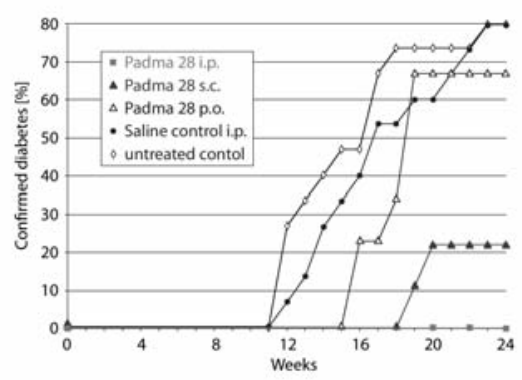

Figure 1. Development of overt diabetes mellitus (confirmed when on two occasions the glucose levels exceeded $1,000 \mathrm{mg} / \mathrm{dL}$ in the urine) in NOD mice with or without treatment with aqueous Padma 28 extract via different routes of administration. While Padma 28 p.o. reduced diabetes incidence by $13 \%$ from $80-67 \%$ compared to the untreated and the saline control groups, it was reduced by $58 \%$ after Padma 28 s.c. administration. In the i.p. treated group development of glucosuria was completely inhibited by Padma 28.

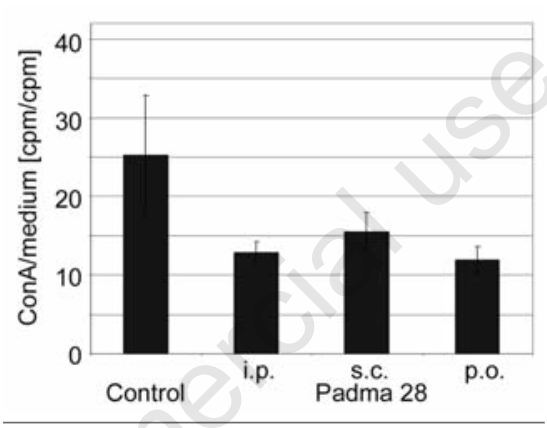

Figure 2. Proliferative response of spleen cells of Padma 28 treated and untreated NOD mice to stimulation with Con A. Padma 28 seems to have anti-proliferative effects confirming earlier studies. ${ }^{22,23}$ In this experiment the data are not statistically significant because of a large variance in the control group.

28 treated animals to the non-specific mitogen Con A was determined. Figure 2 shows an apparent reduction in cell proliferation from animals treated i.p., s.c. and p.o. with Padma 28. Although these values did not reach statistical significance due to a high variance in the control group, nevertheless an anti-proliferative effect of the herbal mixture may be suspected, which is also supported by the results obtained in previous studies..$^{22,23}$

\section{Cytokines in spleen cell super- \\ natants and in plasma}

Upon termination of the trial, the levels of several key cytokines were determined in the plasma and in supernatant fluids from cultured spleen cells. Spleen cells were cultured and stimulated with Con A, and cytokines were measured after 24 and after $48 \mathrm{~h}$. A significant elevation of IL-10, IL-6, IL-4 and INF- $\gamma$ (Figure 3a-d) was
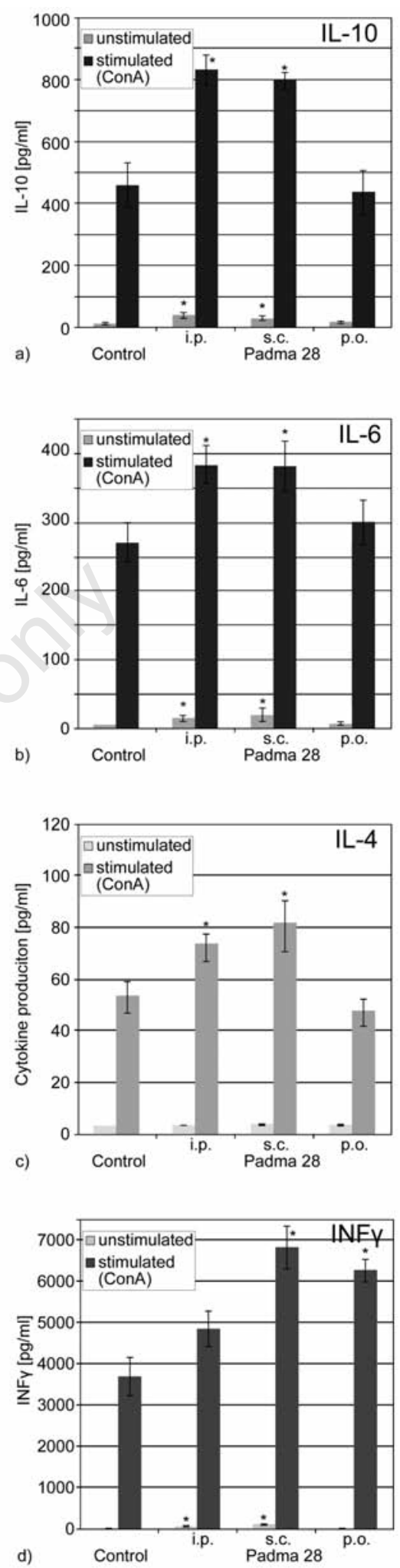

Figure 3. Different cytokines were significantly increased after $48 \mathrm{~h}$ in spleen cells of i.p. or s.c. Padma 28 treated NOD mice compared to controls. Among these were the Th2 cytokines IL-10, IL-6, and IL-4, which are known to have anti-diabetic effects in autoimmune diabetes. Results after $24 \mathrm{~h}$ were similar but less pronounced. 
observed in the supernatant fluids from unstimulated and Con A-stimulated spleen cells obtained from Padma 28 treated mice. In plasma, IL-10 and IL-6 were increased in treated animals as a trend, although only an increase of INF- $\gamma$ in the s.c. group and a decrease of IL-12 in the i.p. group reached statistical significance (Table 1).

\section{Phenotypes of spleen cells involved in autoimmune diabetes in NOD mice}

Since autoimmune insulitis is thought to be caused by $\mathrm{T}$ cells, ${ }^{7,8}$ the phenotypes of lymphocytes involved in the development of diabetes were analyzed. Spleen cells from Padma 28 treated and untreated NOD mice were analyzed by direct immunofluorescence staining for surface markers. The following phenotype markers were tested: CD4, CD4CD25, CD25, CD8, CD69, CD8CD69, and CD11b. A significant decrease in CD8 cells was found in animals treated i.p. with Padma 28 compared to controls (Figure 4). CD8 cytotoxic cells represent $\mathrm{T}$ cells involved in the destruction of the islets. On the other hand, Padma 28 had no effect on the percentages of CD4.

\section{Discussion}

Padma 28 is a complex mixture of secondary plant substances. Essential oils make about $1.1 \%(\mathrm{v} / \mathrm{w})$ and include, among others, eugenol, camphor, 1,8-cineole, geraniol and thymol, which are known to have antiphlogistic and locally analgesic effects, and to inhibit platelet aggregation. ${ }^{24-26}$ Flavonoids are present in the polyherbal preparation at about $0.16 \%(\mathrm{w} / \mathrm{w})$ and include among others isoquercetin, quercetin, luteolin, and apigenin, for some of which anti-hypertensive and anti-inflammatory effects, the ability to improve endothelial function, and oxygen radical scavenging and cytoprotective properties have been shown. ${ }^{27-29}$ Gallotannins and catechin tannins, present in the formula at about $1.1 \%(\mathrm{w} / \mathrm{w})$, are known to have locally anti-inflammatory and anti-oxidative effects. ${ }^{30}$

Different parameters of diabetes mellitus, such as glucosuria, impaired glucose tolerance, insulin content of the pancreas, islet morphology and survival were all favorably influenced by i.p. or s.c. administration of aqueous extracts from Padma 28.

Although the oral route of administration has shown good efficacy in peripheral arterial occlusive disease (PAOD), as shown in various clinical studies and recently also in a metaanalysis, ${ }^{2,46}$ in this NOD model the onset of autoimmune diabetes was delayed in the p.o. group compared to the control groups, but

Table 1. Changes of cytokines in the plasma of Padma 28 treated mice (means \pm SEM, significant values marked in bold and underlined, $\mathrm{P}<0.05)$.

\begin{tabular}{lrcccc} 
pgg/mL & IL-12 & INF- & IL-10 & IL-6 & IL-4 \\
Control & $48.3 \pm 20$ & $<4.1$ & $<6.8$ & $10.26 \pm 2.1$ & $<3.4$ \\
Padma 28 i.p. & $7.1 \pm 1.3$ & $4.2 \pm 0.07$ & $19.4 \pm 13.3$ & $8.89 \pm 4.21$ & $<3.4$ \\
Padma 28 s.c. & $18.5 \pm 4.4$ & $10.3 \pm 1.7$ & $12.45 \pm 5.65$ & $16.63 \pm 3.02$ & $<3.4$ \\
Padma 28 p.o. & $21.5 \pm 1.5$ & $<4.1$ & $<6.8$ & $23.45 \pm 9.6$ & $<3.4$ \\
\hline
\end{tabular}

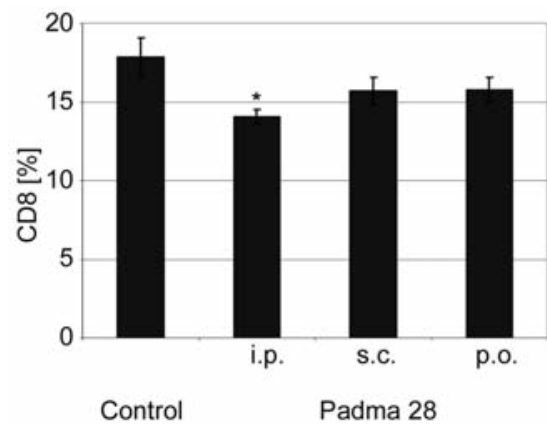

Figure 4. CD8 cells in spleens of Padma 28 and control mice. Reduction was significant in i.p. treated animals.

occurrence of diabetes was not reduced in a statistically significant way at 24 weeks.

Nevertheless, the failure to inhibit the development of diabetes in animals by p.o. administration might be explained on the grounds that following consumption, polyphenols are actively metabolized by the liver and especially by the colonic microbial flora ${ }^{31}$ and that hydroxyl-rich polyphenols can also avidly bind to microbial cells. ${ }^{32}$ Moreover, such avid binding to gut bacteria might also be beneficial for the host since it could prevent toxic polyphenols from entering the blood circulation. ${ }^{33}$

Complex plant formulas such as Padma 28 are known to achieve their effects via multi-target mechanisms, in which the various compounds act simultaneously at different levels of various signaling pathways. ${ }^{34-36}$ The fact that the oral application in the diabetes model did not reach full effectiveness compared to the i.p. and s.c. routes of administration suggests that different or only partially overlapping sets of pleiotropic effects are responsible for the effect on PAOD and type 1 diabetes mellitus, both of which are chronic inflammatory disorders.

Secondary plant substances present in large quantities in Padma 28, ${ }^{37}$ either unaltered or following partial biodegradation, seem to be able to change the cytokine profiles. In our study, as well as in previous works, the herbal preparation induced the generation of the antiinflammatory cytokine IL-10. ${ }^{1}$ The protective effect of IL-10 against autoimmune insulitis is supported by various authors..$^{17,3841}$

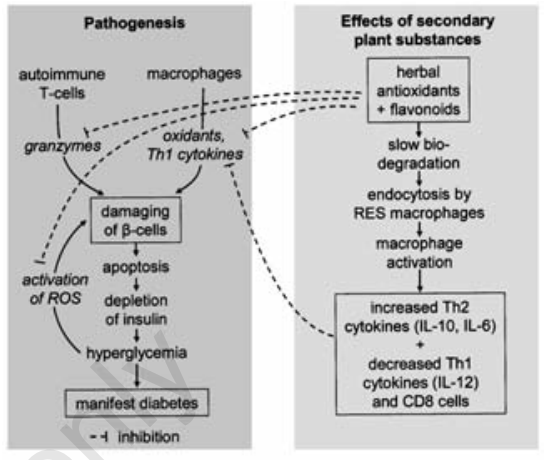

Figure 5. Possible mechanisms by which plant preparations such as Padma 28 might exert anti-diabetic effects.
Additional cytokines, and especially the balance between Th1 and Th2 agents, play a role in autoimmune diabetes, whereby a dominant Th2 immune reaction exerts a protective effect. Animals treated i.p. or s.c. with Padma 28 extract also showed elevated levels of other Th2 cytokines such as IL-4 and IL-6 (Figure 3a-c). However, the production of the proinflammatory marker INF- $\gamma$ also increased, whereas no change was found in the levels of other proinflammatory cytokines. These results were also observed in the plasma of s.c. treated animals (Table 1). In the plasma of Padma 28 treated mice a decrease in Th1 cytokine IL-12 was found, which reached statistical significancy in the i.p. group. The changes in cytokine levels indicate a shift from Th1 to Th2 type immune reaction. This may be due to the sequestration of slowly biodegradable flavonoids and anthocyanidins contained in Padma 28 within macrophages in the reticuloendothelial system, leading to the generation of the Th2 cytokines IL-10 and IL-6, but also to a sharp decrease in IL-12, known to depress the levels of Th2 cytokines.

While non-destructive lesions were found to be associated with the Th2 cytokines IL-4, IL-10 and TGF $\beta,{ }^{42,43}$ several investigations have shown that autoimmune diabetes can be regulated by a delicate balance between the proinflammatory Th1 cytokines INF- $\gamma$, TNF $\beta$, IL-2, IL-12, low frequencies of IL-4, and an increase in the expression of IL-1, TNF $\alpha$ and INF- $\alpha$. $^{44,45}$

It was also shown that treatment with IL-4 or 
IL-10 protected NOD mice from diabetes ${ }^{41,4547}$ thus the elevation of these two cytokines in Padma 28 treated mice may be one mechanism of protection against autoimmune diabetes. Noting this, in contrast to most reports, Serreze et al. discuss the possibility that a Th1-Th2 shift and an increase in IL-10 levels may be the outcome rather than the cause of protection of NOD mice from diabetes. ${ }^{48}$

In addition to the role of cytokines and Th1/Th2 balance in autoimmune diabetes, the involvement of cellular immune systems in the pathogenesis of pancreatic islet destruction is well established. ${ }^{7}$ The role of macrophages in the pathophysiology of diabetes in NOD mice is supported by studies showing that diabetes can be inhibited by macrophage transfer. ${ }^{49} \mathrm{An}$ analysis of the T-cell subsets did not show significant changes in CD11b, CD4, CD25, CD25CD4 and CD69 cells while CD8 cells were reduced following the i.p. treatment (Figure 4). CD8 cells are involved in the development of diabetes as well as in beta cell destruction. ${ }^{15,50}$ Such a reduction in CD8 cells might be induced by antibodies directed against CD8, resulting in protection from diabetes as shown by Solomon and Sarvetnick. ${ }^{51}$

We demonstrated a protective effect induced by the i.p. and s.c. routes of administration of Padma 28 against the development of diabetes in NOD mice. The study also shows different mechanisms by which flavonoids might act on cellular cytokine levels that are at least partly responsible for the overall effect of Padma 28.

The results thus support a pleiotropic mode of action for the herbal multi-compound also in autoimmune diabetes, as was also implied by various in vitro and ex vivo studies employing the whole formula containing other secondary plant substances such as essential oils, flavonoids, and tannins. We propose a pleiotropic mode of action for complex herbal substances inhibiting the development of autoimmune diabetes as summarized in Figure 5 .

\section{Conclusions}

The results of this study indicate that an aqueous extract of Padma 28 has the ability to suppress the development of autoimmune diabetes in female NOD mice. The levels of IL-10 and IL-6 were increased in i.p. and s.c. treated mice and with i.p. administration the proportion of CD8 cells, known to be effectors in beta cell destruction, was reduced. The data suggest a shift of the Th1/Th2 balance towards Th2 immune response which seems to be protective in the development of diabetes. These results support a multi-target mode of action for the complex herbal preparation.

Further studies are needed to elucidate in more detail the protective effects of herbal flavonoids and other secondary plant substances in autoimmune diabetes.

\section{References}

1. Barak V, Kalickman I, Halperin T, et al. PADMA-28, a Tibetan herbal preparation is an inhibitor of inflammatory cytokine production. European Cytokine Network 2004; 15:203-9.

2. Drabaek H, Mehlsen J, Himmelstrup H, et al. A botanical compound, Padma 28, increases walking distance in stable intermittent claudication. Angiology 1993;44: 863-7.

3. Ginsburg I, Sadovnik M, Sallon S, et al. PADMA-28, a traditional Tibetan herbal preparation inhibits the respiratory burst in human neutrophils, the killing of epithelial cells by mixtures of oxidants and proinflammatory agonists and peroxidation of lipids. Inflammopharmacology 1999;7:4762.

4. Melzer J, Brignoli R, Diehm C, et al. Treating intermittent claudication with Tibetan medicine Padma 28: does it work? Atherosclerosis 2006;189:39-46.

5. Moeslinger T, Friedl R, Volf I, et al. Inhibition of inducible nitric oxide synthesis by the herbal preparation Padma 28 in macrophage cell line. Can J Physiol Pharmacol 2000;78:861-6.

6. Sallon S, Beer G, Rosenfeld J, et al. The efficacy of Padma 28, a herbal preparation, in the treatment of intermittent claudication: a controlled double-blind pilot study with objective assessment of chronic occlusive arterial disease patients. J Vascular Investi 1998;4:129-36.

7. Bach JF. Prevent and cure insulin-dependent diabetes. Pathologie-biologie 2003;51: 151-5.

8. Hänninen A, Hamilton-Williams E, Kurts C, et al. Development of new strategies to prevent type 1 diabetes: the role of animal models. Ann Med 2003;35:546-63.

9. Schattner A. Lymphokines in autoimmunity - a critical review. Clin Immunol Immunopathol 1994;70:177-89.

10. Suarez-Pinzon WL, Rabinovitch A. Approaches to type 1 diabetes prevention by intervention in cytokine immunoregulatory circuits. Int J Exp Diabetes Res 2001; 2:3-17.

11. de Waal Malefyt R, Yssel H, Roncarolo MG, et al. Interleukin-10. Curr Opin Immunol 1992;4:314-20.

12. Weiss L, Barak V, Zeira M, et al. Cytokine production in Linomide-treated nod mice and the potential role of a Th (1)/Th(2) shift on autoimmune and anti-inflammatory processes. Cytokine 2002;19:85-93.
13. Fiorentino DF, Zlotnik A, Vieira P, et al. IL10 acts on the antigen-presenting cell to inhibit cytokine production by Th1 cells. J Immunol 1991;146:3445-51.

14. Yssel H, de Waal Malefyt R, Roncarolo MG, et al. IL-10 is produced by subsets of human CD4+ T cell clones and peripheral blood T cells. J Immunol 1992;149:2378-84.

15. Mandrup-Poulsen T. Beta cell death and protection. Ann NY Acad Sci 2003;1005:3242.

16. Sandström J, Jonsson LM, Edlund H, et al. Overexpression of extracellular-SOD in islets of nonobese diabetic mice and development of diabetes. Free Radical Biol Med 2002;33:71-5.

17. Suarez-Pinzon WL, Mabley JG, Strynadka $\mathrm{K}$, et al. An inhibitor of inducible nitric oxide synthase and scavenger of peroxynitrite prevents diabetes development in NOD mice. J Autoimmun 2001;16:449-55.

18. West IC. Radicals and oxidative stress in diabetes. Diabetic Med 2000;17:171-80.

19. Ginsburg I, Kohen R. Cell damage in inflammatory and infectious sites might involve a coordinated "cross-talk" among oxidants, microbial haemolysins and ampiphiles, cationic proteins, phospholipases, fatty acids, proteinases and cytokines (an overview). Free Radical Res 1995;22:489-517.

20. Gross DJ, Leibowitz G, Cerasi E, et al. Increased susceptibility of islets from diabetes-prone Psammomys obesus to the deleterious effects of chronic glucose exposure. Endocrinology 1996;137:5610-5.

21. Gross DJ, Sidi H, Weiss L, et al. Prevention of diabetes mellitus in non-obese diabetic mice by Linomide, a novel immunomodulating drug. Diabetologia 1994;37:1195201.

22. Navab R, Aingorn H, Fallavollita L, et al. PADMA-28, a traditional Tibetan herbal preparation, blocks cellular responses to bFGF and IGF-I. Inflammopharmacology 2004;12:373-89.

23. Jenny M, Schwaiger W, Bernhard D, et al. Apoptosis induced by the Tibetan herbal remedy PADMA 28 in the T cell-derived lymphocytic leukaemia cell line CEMC7H2. J Carcinogen 2005;4:15.

24. Chen SJ, Wang MH, Chen IJ, et al. Antiplatelet and calcium inhibitory properties of eugenol and sodium eugenol acetate. Gen Pharmacol 1996;27:629-33.

25. Nangle MR, Gibson TM, Cotter MA, et al. Effects of eugenol on nerve and vascular dysfunction in streptozotocin-diabetic rats. Planta Medica 2006;72:494-500.

26. Santos FA, Rao VS. Antiinflammatory and antinociceptive effects of 1,8-cineole a terpenoid oxide present in many plant essential oils. Phytotherapy Res 2000;14:240-4.

27. Bischoff SC. Quercetin: potentials in the 
prevention and therapy of disease. Curr Opin Clinical Nutri Metabolic Care 2008;11:733-40.

28. Panda S, Kar A. Apigenin (4',5,7-trihydroxyflavone) regulates hyperglycaemia, thyroid dysfunction and lipid peroxidation in alloxan-induced diabetic mice. Journal Pharmacy Pharmacol 2007;59:1543-8.

29. Seelinger G, Merfort I, Schempp CM. Antioxidant, anti-inflammatory and anti-allergic activities of luteolin. Planta medica 2008;74:1667-77.

30. Wagner H. Arzneidrogen und ihre Wirkungen (Medicinal plants and their effects) 6th ed. Wissenschaftliche Verlagsgesellschaft mbH, Stuttgart, 1999; p.335ff.

31. Sies H. Polyphenols and health: update and perspectives. Arch Biochemi Biophys 2010;501:2-5.

32. Koren E, Kohen R, Ovadia H, et al. Bacteria coated by polyphenols acquire potent oxidant-scavenging capacities. Exp Biol Med (Maywood NJ) 2009;234:940-51.

33. Koren E, Kohen R, Ginsburg I. Polyphenols enhance total oxidant-scavenging capacities of human blood by binding to red blood cells. Exp Biol Med (Maywood NJ) 2010;235:689-99.

34. Csermely P, Ágoston V, Pongor S. The efficiency of multi-target drugs: the network approach might help drug design. Trends Pharmacol Sci 2005;26:178-82.

35. Schwabl H, Vennos C. The "multi-target" approach of Tibetan remedies. Mechanisms of action of Padma 28 in inflammation, with the example of atherosclerosis [translation]. Schweiz Zeitschr GanzheitsMedizin 2006;18:213-8.

36. Ueberall F, Fuchs D, Vennos C. Anti-inflam- matory potential of Padma 28--review of experimental data on the antiatherogenic activity and discussion of the multi-component principle. Res Complementary Natural Classical Med 2006;13:7-12.

37. Samochowiec L, Wieland E. Theoretische, chemische und pharmakodynamische Untersuchungen an PADMA 28. Polbiopharm Reports 1983;20:3-34.

38. Cooke A, Tonks P, Jones FM, et al. Infection with Schistosoma mansoni prevents insulin dependent diabetes mellitus in non-obese diabetic mice. Parasite Immunol 1999;21:169-76.

39. Goudy KS, Burkhardt BR, Wasserfall C, et al. Systemic overexpression of IL-10 induces $\mathrm{CD} 4+\mathrm{CD} 25+$ cell populations in vivo and ameliorates type 1 diabetes in nonobese diabetic mice in a dose-dependent fashion. J Immunol 2003;171:2270-8.

40. Ko KS, Lee M, Koh JJ, et al. Combined administration of plasmids encoding IL- 4 and IL-10 prevents the development of autoimmune diabetes in nonobese diabetic mice. Molecular therapy: the journal of the American Society of Gene Therapy 2001;4:313-6.

41. Pennline KJ, Roque-Gaffney E, Monahan M. Recombinant human IL-10 prevents the onset of diabetes in the nonobese diabetic mouse. Clin Immunology Immunopathol 1994;71:169-75.

42. Gazda LS, Charlton B, Lafferty KJ. Diabetes results from a late change in the autoimmune response of NOD mice. $J$ Autoimmun 1997;10:261-70.

43. Shehadeh NN, LaRosa F, Lafferty KJ. Altered cytokine activity in adjuvant inhibition of autoimmune diabetes. J Autoimmun 1993;6:291-300.
44. Rabinovitch A, Suarez-Pinzon WL, Sorensen 0, et al. IFN-gamma gene expression in pancreatic islet-infiltrating mononuclear cells correlates with autoimmune diabetes in nonobese diabetic mice. J Immunol 1995;154:4874-82.

45. Rabinovitch A. An update on cytokines in the pathogenesis of insulin-dependent diabetes mellitus. Diabetes/Metabolism Rev 1998;14:129-51.

46. Rapoport MJ, Jaramillo A, Zipris D, et al. Interleukin 4 reverses $\mathrm{T}$ cell proliferative unresponsiveness and prevents the onset of diabetes in nonobese diabetic mice. $\mathrm{J}$ Exp Med 1993;178:87-99.

47. Szelachowska M, Kretowski A, Kinalska I. Decreased in vitro IL-4 [corrected] and IL10 production by peripheral blood in first degree relatives at high risk of diabetes type-I. Hormone Metabolic Res 1998;30: 526-30.

48. SerrezeDV, Chapman HD, Post CM, et al. Th1 to Th2 cytokine shifts in nonobese diabetic mice: sometimes an outcome, rather than the cause, of diabetes resistance elicited by immunostimulation. J Immunol 2001;166:1352-9.

49. Yagi H, Matsumoto M, Suzuki S, et al. Possible mechanism of the preventive effect of BCG against diabetes mellitus in NOD mouse. I. Generation of suppressor macrophages in spleen cells of BCG-vaccinated mice. Cell Immunol 1991;138:130-41.

50. Tsai S, Shameli A, Santamaria P, et al. CD8+ T cells in type 1 diabetes. Adv Immunol 2008;100:79-124.

51. Solomon M, Sarvetnick N. The pathogenesis of diabetes in the NOD mouse. Adv Immunol 2004;84:239-64. 